\section{Partners in basic education}

The publication of this special edition of the South African Journal of Communication Disorders, 'Speech-Language Therapists and Audiologists as Partners in Basic Education, contributes to our transformation. It is part of a series of other activities under the auspices of the South African Speech-Language-Hearing Association, aiming to reposition our professions so they can contribute effectively to development in South Africa. At the 2010 SASLHA conference, 'New Directions', there were several inputs highlighting the national crisis in basic education and the potential role the professions could play in improving education outcomes. The conference led to formation of the Education Task Team, who considered a series of activities to advance our future practice. It was recognised that interventions in basic education must be relevant to the South African context and that new and different knowledge was needed. As a first step it was imperative to document the current issues and available knowledge - hence the idea for this dedicated special edition of SAJCD. It is envisaged that research in the domain of basic education will continue to grow as we shape our practices in a rapidly changing social milieu.

We are also aware that South Africa is part of a global community that must participate in the international dialogue on practice. We have therefore invited Professor Barbara Ehren, an expert in schoolbased interventions, to provide a response to the lead article which contextualises the argument for renewed roles for speech-language therapists and audiologists in basic education in South Africa. We recognise that we are at the beginning of a seemingly daunting task, but believe that an accumulation of relevant knowledge as well as strategic actions on our part will result in positive contributions to nationbuilding.

\section{Harsha Kathard}

Editor: Special Edition SAJCD 